\title{
Comparison of visual results and quality of vision after
implantation of trifocal intraocular lenses versus bifocal intraocular lenses
}

\section{Comparación de resultados visuales y de calidad de visión después del implante bilateral de lentes intraoculares trifocales frente a lentes intraoculares bifocales}

\author{
Diego Zamora-de-la-Cruz*, Marisol Garzón and Eduardo Chávez-Mondragón \\ Anterior Segment Department, Instituto de Oftalmología Fundación Conde de Valenciana I.A.P., Ciudad de México, México
}

\begin{abstract}
Objective: To determine and compare the visual results between the bilateral ReSTOR +2.50 bifocal intraocular lens (IOL) implantation and the PanOptix trifocal IOL in patients with cataract and presbyopia at the Instituto de Oftalmología Fundación Conde de Valenciana in Mexico City. Material and methods: 24 eyes of 12 patients with ReSTOR +2.50 and PanOptix implantation were evaluated in the Instituto de Oftalmología Fundación Conde de Valenciana over a period of six months. Best-corrected visual acuity was evaluated at different distances (far, intermediate and near), as well as contrast sensitivity under photopic conditions at different spatial frequencies. A monocular defocus curve was performed and the VFQ-25 questionnaire was evaluated. Results: Far visual acuity was good in both groups, although the differences in intermediate and near visual acuity were clinically and statistically significant between both IOLs, differences that favored the PanOptix IOL. The contrast sensitivity tests did not show remarkable differences between both lenses. The results of the VFQ-25 questionnaire for both lenses were high and did not show significant differences between them. Conclusions: Both lenses exhibit good acceptance among patients. Currently, the only acceptable criterion for deciding between one lens and another is based on the patient's visual needs, which are closely related to age and the activities performed by the patient.
\end{abstract}

Key words: Intraocular lenses. Presbyopia. Phacoemulsification. Contrast sensitivity.

\section{Resumen}

Objetivo: Determinar y comparar los resultados visuales entre el implante bilateral de lente intraocular (LIO) bifocal ReSTOR +2.50 y LIO trifocal PanOptix en pacientes con catarata y presbicia en el Instituto de Oftalmología Fundación Conde de Valenciana en Ciudad de México. Material y métodos: Se evaluaron 24 ojos de 12 pacientes con implante de ReSTOR +2.50 y PanOptix en el Instituto de Oftalmología Fundación Conde de Valenciana en un periodo de seis meses. Se evaluaron la agudeza visual mejor corregida, a diferentes distancias (de lejos, intermedia y de cerca), y la sensibilidad al contraste en condiciones fotópicas a diferentes frecuencias espaciales. Se realizó una curva de desenfoque monocular y se evaluó el cuestionario VFQ-25. Resultados: Las agudezas visuales de lejos fueron buenas en ambos grupos, aunque las diferencias de agudezas visuales intermedias y de cerca fueron clínica y estadísticamente significativas entre ambos LIO, diferencias que favorecieron a lio PanOptix. Las pruebas de sensibilidad al contraste no mostraron diferencias notables entre ambos

\section{Correspondence:}

*Diego Zamora-de-la-Cruz E-mail: diegozamora@me.com

Available online: 07-05-2018

Date of reception: 10-02-2017

Date of acceptance: 06-10-2017 DOI: 10.24875/RMOE.M18000004

\section{Rev Mex Oftalmol (Eng). 2018;92(2):62-69} www.rmo.com.mx

2604-1731/(O 2017 Sociedad Mexicana de Oftalmología. Published by Permanyer México SA de CV. This is an Open Access article under the CC BY-NC-ND license (http://creativecommons.org/licenses/by-nc-nd/4.0/). 
lentes. Los resultados de la encuesta VFQ-25 para ambos lentes fueron altos y no mostraron diferencias importantes entre sí. Conclusiones: Ambos lentes muestran tener buena aceptación entre los pacientes. Parece ser que, actualmente, el único criterio aceptable para decidir entre un lente u otro se basa básicamente en las necesidades de visión del paciente, que están íntimamente relacionadas con la edad y las actividades que éste realice.

Palabras clave: Lentes intraoculares. Presbicia. Facoemulsificación. Sensibilidad al contraste.

\section{Introduction}

Today, cataract is the main cause of reversible blindness in the world and in our country ${ }^{1}$. Cataract surgery, specifically phacoemulsification, is the most common ophthalmic procedure performed worldwide. With the advancement of technology, the development of new IOLs has increased, which are intended to restore the original function of the crystalline lens to focus on objects at different distances: far, intermediate and near.

Multifocal IOLs are based on diffractive optics to achieve different ranges of vision (near, intermediate and far), which means that they divide light into several focal points: one for near vision, another for intermediate vision and another for far vision, with the purpose of correcting the presbyopia associated with the loss of the accommodation capacity of the crystalline lens with increasing age $\mathrm{e}^{2-4}$.

Currently, diffractive IOL designs have been developed, such as ReSTOR +2.50 (Alcon, Forthworth TX, USA). This and other multifocal IOLs seek to develop aspheric profiles with low addition and non-rotational symmetry to achieve better vision ranges, among which intermediate vision is also found $(60-80 \mathrm{~cm})^{4-6}$.

The ReSTOR +2.50 lens (SV25T0) is a multifocal and bifocal IOL indicated for patients who need to work at intermediate distances, especially at a distance of 40$70 \mathrm{~cm}$. It has concentric rings in the central area that give patients $\mathrm{a}+2.50$ addition in the central part in the plane of aerial eyeglasses.

This lens is manufactured with an aspheric profile, composed of flexible hydrophobic acrylic with a refractive index of 1.55 , an asphericity of -0.2 , a biconvex apodized design and with seven concentric rings in the center. The diameter of the central region is of $0.938 \mathrm{~mm}$, the diameter of the optic is $6 \mathrm{~mm}$, the total diameter is $13 \mathrm{~mm}$ and the internal diffractive structure is $3.4 \mathrm{~mm}$. The external refractive structure is $2.6 \mathrm{~mm}$, it has no angulation in the haptic and its edges are square ${ }^{7}$.

The center and the peripheral region of the lens are 9.6 and $8.3 \%$ longer, respectively, than its predecessor, the ReSTOR +3.0 lens, that is, 0.938 versus 0.856 for the center, and 2.6 versus 2.4 for the periphery, respectively. When implanted bilaterally, patients achieve excellent vision (intermediate and far) with a near vision point.

Another lens also manufactured by the same company is the Acrysof IQ PanOptix (TFNT00). This new multifocal and trifocal IOL aims not to sacrifice near vision as does the ReSTOR 2.50 and it has a much wider range of vision ${ }^{8}$.

The Acrysof IQ PanOptix lens is indicated for patients who need to work at intermediate and near distances, specifically at $0.4,0.6$ and $0.8 \mathrm{~m}$ distances. It has concentric rings in the central part of the optic of $4.5 \mathrm{~mm}$ that allow a lower degree of pupil dependency compared to other multifocal lenses. The lens was designed to have four focal points: one near, two intermediate and one far.

This lens is manufactured with an aspheric profile and is composed of flexible hydrophobic acrylic with a refractive index of 1.55 , as well as the well-known and already evaluated Acrysof IQ platform. It has an asphericity of -0.2 with 15 concentric rings in its center. The diameter of the optic is $6 \mathrm{~mm}$ and the total diameter is $13 \mathrm{~mm}$, the internal diffractive structure is $4.5 \mathrm{~mm}$ and the external refractive structure is $1.5 \mathrm{~mm}$.

Both PanOptix and ReSTOR +2.50 are designed to be placed in the capsular bag, and a continuous circular capsulorhexis of no more than $5 \mathrm{~mm}$ is ideal during surgery. When implanted bilaterally, patients achieve excellent intermediate and near vision without significantly sacrificing far vision ${ }^{9-14}$.

The adverse visual effects secondary to the implantation of diffractive multifocal lenses are glare, difficulty seeing in low light (decreased contrast sensitivity) and halos, among others ${ }^{4,10,15}$. However, when performing contrast sensitivity tests on patients implanted with this lens, it has been observed that they did not show a clinically significant decrease in contrast sensitivity ${ }^{16}$.

Currently, there are no studies showing the long-term prognosis of the bilateral implant of ReSTOR +2.50 or Acrysof IQ PanOptix IOLs in Mexican patients who are emmetropic and free of comorbidities. In addition, the 
adverse effects of the ReSTOR +2.50 versus the PanOptix lens in patients with cataract and presbyopia have not yet been compared as in other studies ${ }^{10}$.

The ReSTOR lens has been previously evaluated, with very good results regarding visual acuity and contrast sensitivity ${ }^{9,10,13}$.

Visual adverse effects, such as halos and glare have been widely described, especially under mesopic conditions, although these do not seem to have a significant impact on the quality of life of patients; however, it depends on the type of activity performed by them $8,10,17-19$.

The patient's quality of life is directly related to the patient's vision, which is why the USA National Eye Institute developed a validated 25 -item Likert scale (VFQ-25-NEI) that measures quality of life associated with visual problems. This survey determines different components, including visual satisfaction regarding near vision, far vision, peripheral vision, color vision, social function depending on vision and even activities such as driving ${ }^{20,21}$.

There are different methods to evaluate contrast sensitivity in patients implanted with multifocal lenses, among which the contrast sensitivity table Function Acuity Contrast Sensitivity Test is widely used under photopic conditions at $85 \mathrm{~cd} / \mathrm{m}^{2,16}$.

The implantation of a multifocal IOL after cataract surgery is performed in patients without apparent ophthalmological disorders, since it is known that there is a marked loss of contrast sensitivity due to diffraction. However, it is believed that the loss is not significant for the ReSTOR +2.50 lens $^{22,23}$, although this phenomenon has not yet been thoroughly studied in the Mexican population. Another purpose of this study is to evaluate if the ReSTOR +2.50 decreases contrast sensitivity significantly in order to offer multifocality to patients in whom this technology is contraindicated.

The implantation of an IOL with more than two focal points, as is the case with PanOptix, allows restoration of vision at different distances, which translates initially into a better quality of life for patients. However, it is known that the greater the diffraction of light through a medium, like in this lens, the visual adverse effects increase ${ }^{8,10,17-19}$. The Acryosof IQ PanOptix lens offers an extended vision in four focal points that allows taking advantage of the light that passes through the optic up to $88 \%$, and this allows a lower contrast sensitivity loss compared to other conventional trifocal lenses ${ }^{7}$.

It is important to determine if an IOL with different focal points is effective and to demonstrate possible advantages or disadvantages of this technology compared to other multifocal lenses with three or two focal points.

We intend to evaluate the quantity/quality of vision in patients implanted bilaterally with the ReSTOR +2.50 and the PanOptix, to determine the loss of contrast sensitivity with both lenses and the impact that both vision and quality of vision have on the quality of life of the Mexican population.

Knowing precisely the effect it has on the Mexican population allows us to offer patients the best options for presbyopia in the context of cataract surgery.

\section{General objectives}

To determine objective and subjective visual data in patients with cataract and presbyopia implanted with ReSTOR +2.50 and PanOptix IOLs, to compare the results and determine if there is a clinical/statistical difference between them.

\section{Material and methods}

This is an observational, longitudinal and prospective study carried out in the Anterior Segment Department of the Instituto de Oftalmología Fundación Conde de Valenciana I.A.P., in Mexico City. Candidates were enrolled consecutively for multifocal IOL implantation, without ocular comorbidities, with astigmatism $<1$ diopter, with no history of previous eye surgery and that could comply with long-term follow-up. Patients who could not be implanted bilaterally with the same IOL or who had alterations that conditioned bias of the results were excluded from the study.

Preoperative evaluation is carried out systematically. Multifocal PanOptix or ReSTOR IOL are offered randomly to the candidate patients, and the advantages and disadvantages of each IOL are explained to them. The surgery is carried out by two surgeons of the Anterior Segment Department of the Instituto de Oftalmología Fundación Conde de Valenciana I.A.P. (ECM and DZC), and the technique used was stop and chop.

All the patients were explained the advantages and disadvantages described by the company, and they chose the lens depending on their needs and personal activities.

We identified 14 eyes with ReSTOR +2.50 implant and 10 eyes with PanOptix implant in the Instituto de Oftalmología Fundación Conde de Valenciana I.A.P., which were operated from March 1 to August 31, 2016.

The patients who were operated during the aforementioned period were called and examined; a 
process performed six months after the surgery in all patients.

The best-corrected monocular visual acuity was evaluated in all patients with the ETDRS chart at $3 \mathrm{~m}$ and 60 and $33 \mathrm{~cm}$ with the ETDRS chart for far, intermediate and near vision, respectively. A monocular defocus curve was performed on all patients with the ETDRS chart at $4 \mathrm{~m}$.

Contrast sensitivity parameters were evaluated using the FACT contrast sensitivity chart, with the refraction of the corrected visual acuity and after instillation of ocular lubricants.

Measurement of contrast sensitivity was made at a distance of $3 \mathrm{~m}$ with the chart; the illumination during the test was $85 \mathrm{~cd} / \mathrm{m}^{2}$.

Contrast sensitivity values were captured at different frequencies (1.5, 3, 6, 12 and 18 cycles per degree) and this value was transformed into logarithmic notation for statistical analysis (LogCS).

The quality of life survey VFQ-25 of the US National Eye Institute (VFQ-25-NEI) was administered with the format translated into Mexican Spanish (validated) at the end of the examination of patients in both groups.

Next, tonometry was performed and a mydriatic was instilled in order to observe if there was opacity of the posterior capsule, since this could interfere with the results of the study; in this case the patient was scheduled to perform YAG laser capsulotomy with the patient re-scheduled after 15 days to perform the evaluation again.

Initially, we divided the population obtained in two groups: the first with ReSTOR +2.50 and the second with PanOptix. The analysis was monocular.

Correlation tests (Spearman) were performed among the variables of contrast sensitivity, visual acuity and the validated VFQ-25 questionnaire, as well as non-parametric tests (Mann-Whitney $U$ ) to compare means and determine if there were statistically significant differences regarding visual acuity, contrast sensitivity, and the VFQ-25 questionnaire.

The statistical program SPSS20.0 was used in addition to Microsoft Excel to capture the data.

\section{Results}

Twenty-four eyes of 12 patients were analyzed. In the population, a comparable number of lenses was implanted in both eyes: ReSTOR (58.33\%) and PanOptix (41.67\%), as shown in Figure 1.

The following visual acuities were found in both groups at different working distances, as shown in

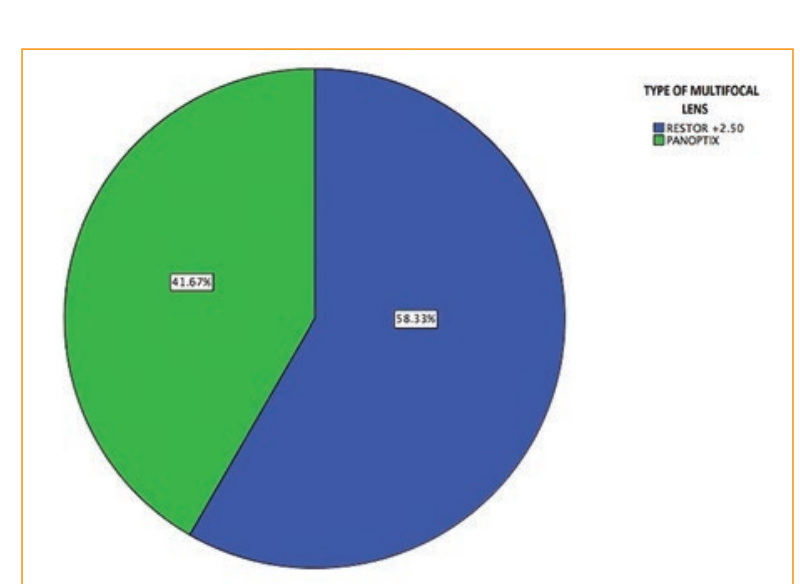

Figure 1. ReSTOR versus Pan0ptix: proportion of patients implanted during the study.

Figure 2. For plot analysis, it should be noted that this is estimated with LogMAR logarithmic units and the graph is inverted (-1) for a better comparative analysis.

The latter shows how the average visual acuity in both groups is remarkably good; at intermediate and near distances, the values are significantly better in the PanOptix group, despite the fact that ReSTOR's commercial information favors intermediate vision in patients. A Mann-Whitney Test was performed, with which statistically significant differences were observed for intermediate and near vision $(p<0.004$ and $p<0.002)$ (Fig. 3).

The defocus curve is shown in both groups. The results of another multifocal lens implanted in our institution (Physiol/Finevision) are added, whose research was carried out in parallel ( $n=25)$ (Fig. 4).

The defocus curve of the ReSTOR +2.50 lens is as expected in the medical literature, that is, it falls into near vision. The other two plots representing IOLs with three or more focal points also show good visual acuity in a wider range of vision (from 4 to $3 \mathrm{~cm}$ ).

The results of the contrast sensitivity test in both groups are shown in Figure 5.

We established the normal limits of contrast sensitivity at different frequencies. The red and green lines are the means of contrast sensitivity at different spatial frequencies of both lenses, and are adjacent to the normal lower limit, so there is no significant difference when comparing both groups at any given frequency $(p>0.315)$.

None of our patients required capsulotomy due to opacity of the posterior capsule during the data collection process. 


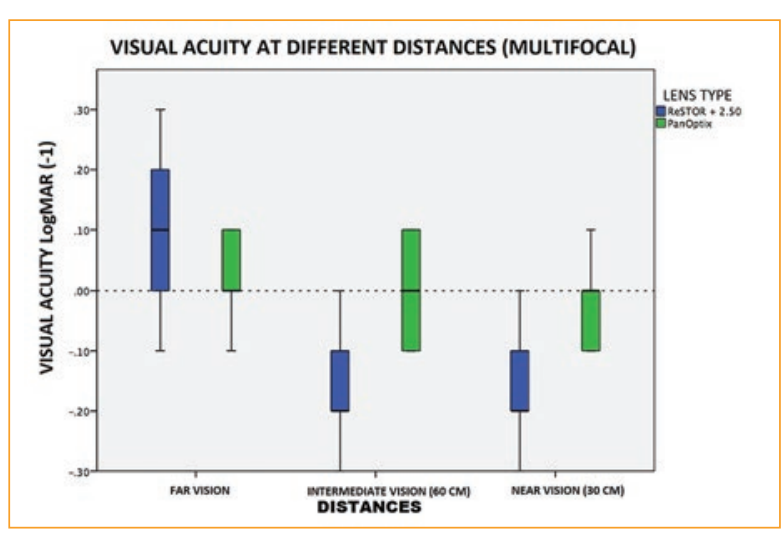

Figure 2. Visual acuity at different distances for both IOLs (Far, Intermediate and Near).

Table 1 shows the values of the VFQ-25 questionnaire with different ReSTOR and PanOptix IOLs. The values are high in most of the subscales of the VFQ-25. When performing the comparative test for both IOLs in the different subscales and the general value of the VFQ-25, no significant differences were observed $(p>0.341)$. It was not possible to compare activities such as driving, since the patients of the PanOptix group do not drive. Excluding items such as driving does not change the final score of the VFQ-25, because the questionnaire allows it.

Correlation was made between the variables of the VFQ, visual acuity and contrast sensitivity, which did not yield data that could be valuable for the study. No relationship was found between VFQ and visual acuity or contrast sensitivity.

\section{Discussion}

Today, the ReSTOR +2.50 and PanOptix IOLs are a good option for restoring near vision after cataract surgery, and they continue to be well accepted among anterior segment surgeons.

We know that the IOL's own design allows them to have different optimal vision distances. While the ReSTOR $+2.50 \mathrm{IOL}$ gives preference to intermediate and far vision, the PanOptix IOL allows patients greater independence from eyeglasses and good vision from 4 $\mathrm{m}$ to $30 \mathrm{~cm}$, as shown in the defocus curve. In our study, a statistically significant difference was found according to the Mann-Whitney $U$ Test, favoring the PanOptix IOL for intermediate and near vision.

Obviously, we should emphasize the adverse effects that have been observed with this type of lens, such as glare, and halos around lights. These first-order effects seem to be more frequent in patients who were implanted with the PanOptix IOL, and this situation could be due to the number of rings and the size of the diffractive zone that this lens has ${ }^{24}$. During the study, all the implanted patients with ReSTOR and PanOptix reported glare/halos phenomena in the immediate postoperative period, which eventually disappeared. This phenomenon could not be quantified objectively. The measurement of Point Spread Function was performed independently with the OPD III (Nidek) at six months for all patients. The results showed no evidence of objective halos in any of the two groups or results as those shown by Gatinel et al. ${ }^{24}$.

In terms of visual satisfaction, both lenses were within acceptable ranges if we take as premise that the highest score is 100 within the VFQ-25 score. The values presented in our work are excellent. Once the comparison between both lenses was made, no statistically significant difference was found between the two, favoring the theory that both lenses contribute to a good quality of life and visual satisfaction. It was previously established that these scores are clinically and statistically significant compared to monofocal lenses ${ }^{25}$.

It is essential to emphasize that we must take into consideration the occupation of our patients, in addition to the visual demands, since their visual satisfaction depends directly on this. It would be preferable in patients who still have work demands in computers/offices to consider PanOptix, since these lenses provide a greater range of vision, and consider ReSTOR in those patients whose job demands directly depend on vision under low illumination.

It was found that, when comparing contrast sensitivity values between both lenses, there was no clinically or statistically significant difference between them, which is why it should not be a criterion to choose between one lens and another. These results confirm that multifocal IOLs should not be used in cases in which contrast sensitivity is low.

When performing the comparison with the VFQ-25 score, the scores in activities such as driving (ReSTOR group) or color discrimination are not as low as expected, and the general score of the VFQ-25 questionnaire in both cases is comparable with each other.

The strength of both lenses continues to be their design, the square edges and their haptics, which give them a lower index of opacity of the posterior capsule. This has certain advantages, such as less need of YAG laser capsulotomy and consequently fewer complications that diminish long-term vision. The design has been widely 
Table 1. Comparison of results of the VFQ-25 questionnaire (overall results and specific subscales results)

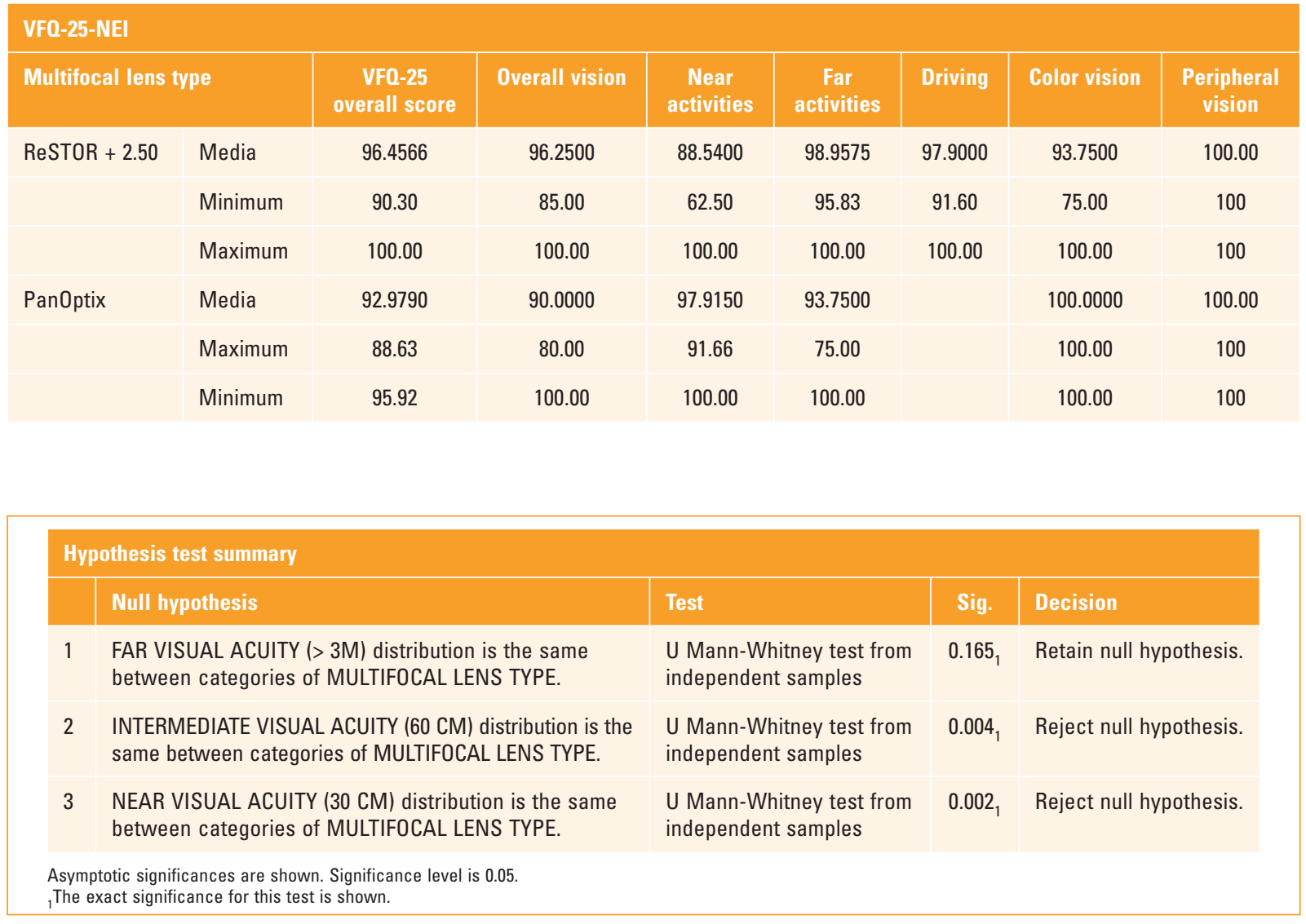

Figure 3. Summary of the hypothesis test. Vision is significantly better with PanOptix according to the image above.

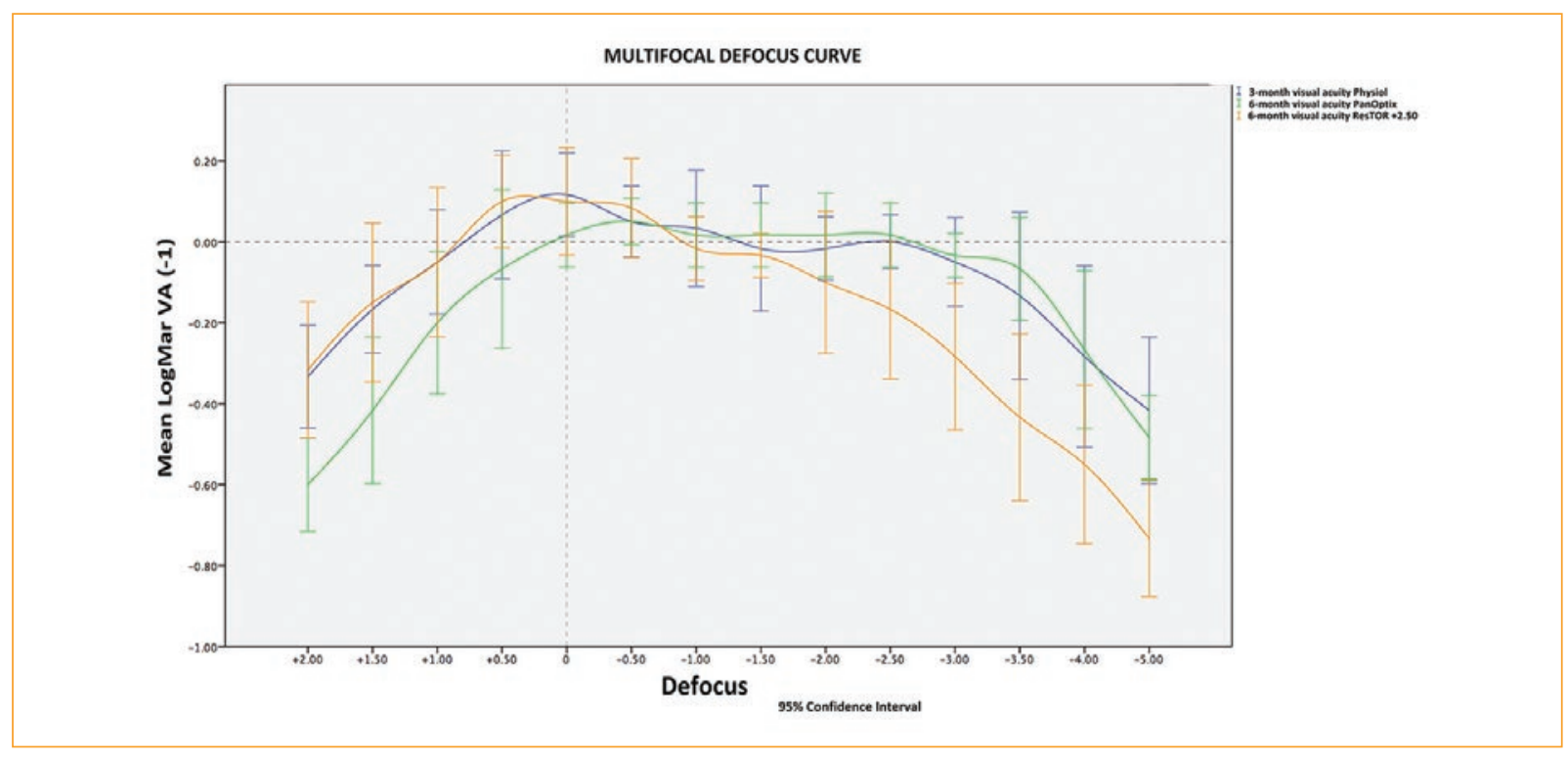

Figure 4. Defocus curve. Three IOLs are compared -Physiol (Fine vision), Pan0ptix (Alcon) and ReSTOR (+2.50), six months after surgery. Data for the Physiol curve were obtained from another study conducted at the same time in the Instituto de Oftalmología Fundación Conde de Valenciana. 


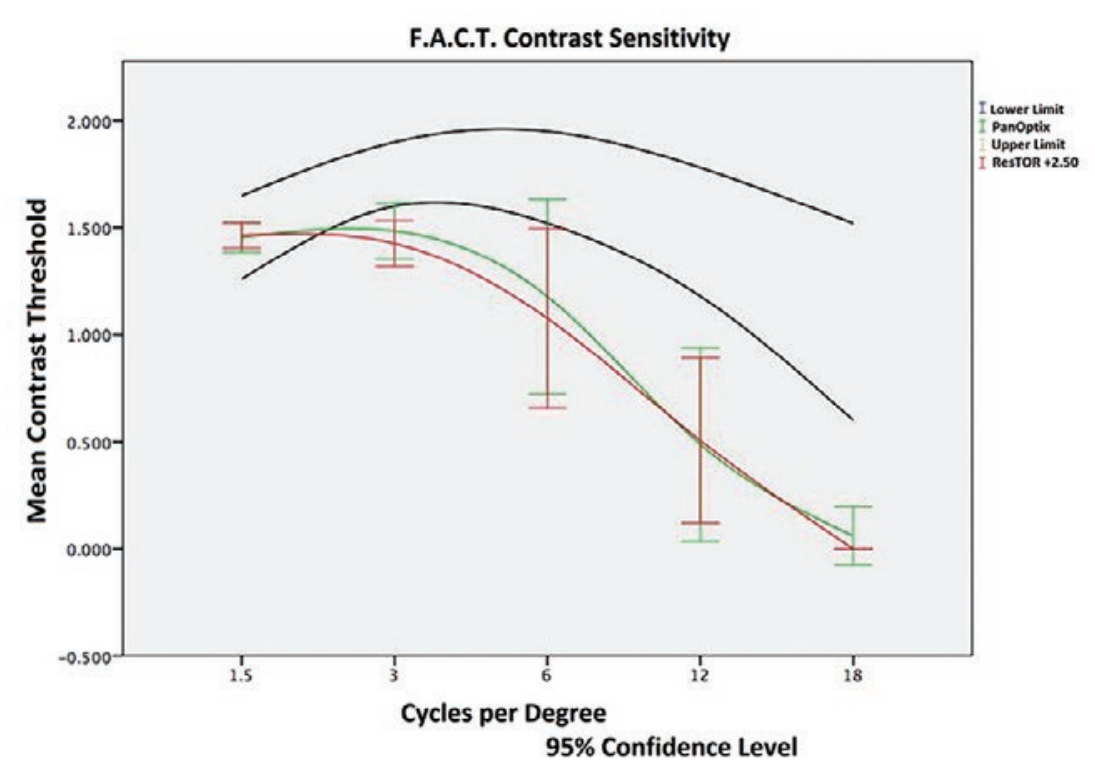

Figure 5. Contrast sensitivity test under photopic conditions. Comparison of PanOptix and Physiol. Black lines show the range of normality through frequencies.

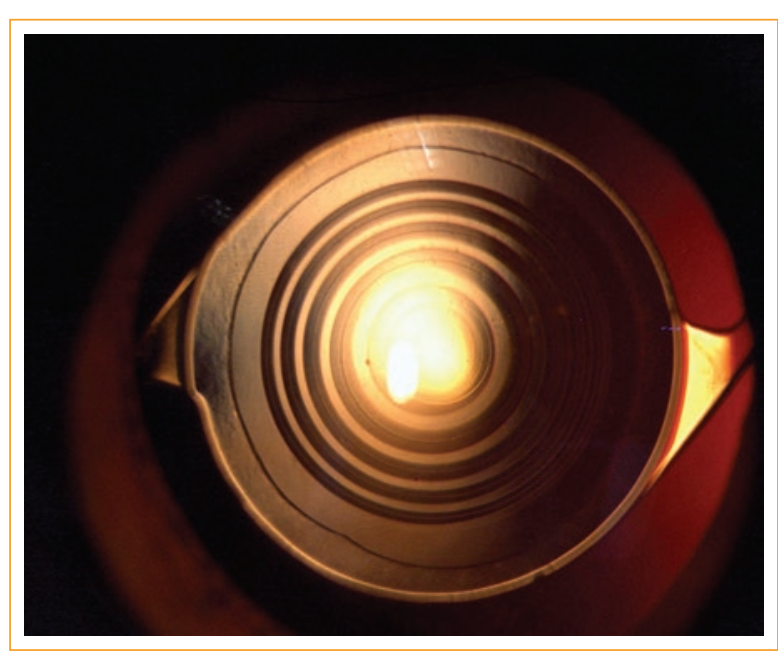

Figure 6. Pan0ptix IOL by retroillumination.

accepted among cataract surgeons for the comfort and safety of its implantation in the capsular bag (Fig. 6).

The study allowed to determine the contrast sensitivity in patients implanted with ReSTOR +2.50 compared to PanOptix. Despite a lower number of rings (ReSTOR), contrast sensitivity is similar, so it should not be recommended in patients with comorbidities that decrease contrast sensitivity.

The study has certain weaknesses, such as not being a multicentric study and the limited size of the sample; however, it can provide us with valuable data when choosing a multifocal lens.

Both lenses proved to be very well accepted by patients, and it seems that adverse effects such as glare are related to the number of rings; glare may or may not disappear with the patient's neuroadaptation.

\section{Conclusions}

When comparing both lenses, a clinically and statistically significant difference was observed regarding near or intermediate vision favoring PanOptix. There were no differences between both lenses regarding contrast sensitivity.

The differences between both lenses in the validated VFQ-25-NEI visual satisfaction questionnaire were not significant. The scores were high for both lenses.

The latter implies that, when deciding which lens to implant in a patient, the criterion must be based mainly on the vision needs/activities of the patient and in their economic possibilities.

There has been speculation regarding the end of multifocal and bifocal IOLs such as ReSTOR; however, it seems that the answer depends directly on the commercial value of the IOL.

Knowing the needs of the patient, as well as their activities, is of utmost importance in order to offer the right lens that corrects presbyopia after cataract 
surgery. Today both lenses remain an excellent option, especially for those patients who are retired and whose visual needs are not so high under dim conditions.

\section{Funding}

No funding has been granted for this research and the authors declare no commercial interest in this protocol.

\section{Conflict of interest}

There is no conflict of interest of the investigators in this study.

\section{Ethical disclosures}

Protection of human and animal subjects. The authors declare that the procedures followed were in accordance with the regulations of the relevant clinical research ethics committee and with those of the Code of Ethics of the World Medical Association (Declaration of Helsinki).

Confidentiality of data. The authors declare that they have followed the protocols of their work center on the publication of patient data.

Right to privacy and informed consent. The authors have obtained the written informed consent of the patients or subjects mentioned in the article. The corresponding author is in possession of this document.

\section{References}

1. Dawson CR, Schwab IR. Epidemiology of cataract - a major cause of preventable blindness. Bull World Health Organ. 1981;59(4):493-501.

2. Auffarth GU, Dick HB. Multifocal intraocular lenses: a review. Ophthalmologe. 2001;98(2):127-7.

3. Bellucci R. Multifocal intraocular lenses. Curr Opin Ophthalmol. 2005;16(1):33-7.

4. Braga-Mele R, Chang D, Dewey S, et al. Multifocal intraocular lenses: relative indications and contraindications for implantation. J Cataract Refract Surg. 2014;40(2):313-22.

5. Davison JA, Simpson MJ. History and development of the apodized diffractive intraocular lens. J Cataract Refract Surg. 2006;32(5):849-58.
6. Lehmann R, Waycaster C, Hileman K. A comparison of patient-reported outcomes from an apodized diffractive intraocular lens and a conventional monofocal intraocular lens. Curr Med Res Opin. 2006;22(12): 2591-602.

7. Madrid-Costa D, Ruiz-Alcocer J, Ferrer-Blasco T, García-Lázaro S, Montes-Mico R. Optical quality differences between three multifocal intraocular lenses: bifocal low add, bifocal moderate add, and trifocal. J Refract Surg. 2013;29(11):749-54.

8. Lee S, Choi M, Xu Z, Zhao Z, Alexander E, Liu Y. Optical bench performance of a novel trifocal intraocular lens compared with a multifocal intraocular lens. Clin Ophthalmol. 2016:10:1031-8.

9. Gundersen KG, Potvin R. Comparative visual performance with monofocal and multifocal intraocular lenses. Clin Ophthalmol. 2013;7:1979-85.

10. Hayashi K, Ogawa S, Manabe SI, Hirata A. Visual outcomes in eyes with a distance-dominant diffractive multifocal intraocular lens with low near addition power. Br J Ophthalmol. 2015;99(11):1466-70.

11. Hutz WW, Eckhardt HB, Rohrig B, Grolmus R. Reading ability with 3 multifocal intraocular lens models. J Cataract Refract Surg. 2006; 32(12):2015-21.

12. Hutz WW, Eckhardt HB, Rohrig B, Grolmus R. Intermediate vision and reading speed with array, Tecnis, and ReSTOR intraocular lenses. J Refract Surg. 2008;24(3):251-6.

13. Ji J, Huang X, Fan X, Luo M. Visual performance of Acrysof ReSTOR compared with a monofocal intraocular lens following implantation in cataract surgery. Exp Ther Med. 2013:5(1):277-81.

14. Kohnen $T$, Nuijts R, Levy $P$, Haefliger $E$, Alfonso JF. Visual function after bilateral implantation of apodized diffractive aspheric multifocal intraocular lenses with a +3.0 D addition. J Cataract Refract Surg. 2009:35(12):2062-9.

15. Pieh $\mathrm{S}$, Weghaupt $\mathrm{H}$, Skorpik $\mathrm{C}$. Contrast sensitivity and glare disability with diffractive and refractive multifocal intraocular lenses. J Cataract Refract Surg. 1998;24(5):659-62.

16. Mayer S, Bohm T, Haberle H, Pham DT, Wirbelauer C. [Combined implantation of monofocal and multifocal intraocular lenses for presbyopia correction in cataract patients]. Klin Monbl Augenheilkd. 2008;225(9):812-7.

17. Pedrotti E, Mastropasqua $R$, Passilongo M, Parisi G, Marchesoni I, Marchini G. Comparison of two multifocal intraocular lens designs that differ only in near add. J Refract Surg. 2014;30(11):754-60.

18. Maurino V, Allan BD, Rubin GS, Bunce C, Xing W, Findl O. Quality of Vision after Bilateral Multifocal Intraocular Lens Implantation: A Randomized Trial - AT LISA 809M versus AcrySof ReSTOR SN6AD1. Ophthalmology. 2015;122(4):700-10.

19. Carson D, Xu Z, Alexander E, Choi M, Zhao Z, Hong X. Optical bench performance of 3 trifocal intraocular lenses. J Cataract Refract Surg. 2016;42(9):1361-7.

20. Zhang F, Sugar A, Jacobsen G, Collins M. Visual function and spectacle independence after cataract surgery: bilateral diffractive multifocal intraocular lenses versus monovision pseudophakia. J Cataract Refract Surg. 2011;37(5):853-8.

21. Voskresenskaya A, Pozdeyeva N, Pashtaev N, Batkov Y, Treushnicov V, Cherednik V. Initial results of trifocal diffractive IOL implantation. Graefes Arch Clin Exp Ophthalmol. 2010;248(9):1299-306.

22. Castillo-Gómez A, Carmona-González D, Martínez-de-la-Casa JM, Palomino-Bautista C, García-Feijoo J. Evaluation of image quality after implantation of 2 diffractive multifocal intraocular lens models. J Cataract Refract Surg. 2009;35(7):1244-50.

23. Santhiago MR, Wilson SE, Netto MV, et al. Modulation transfer function and optical quality after bilateral implantation of $\mathrm{a}+3.00 \mathrm{D}$ versus $\mathrm{a}+4.00$ D multifocal intraocular lens. J Cataract Refract Surg. 2012;38(2):215-20.

24. Gatinel D, Loicq J. Clinically Relevant Optical Properties of Bifocal, Trifocal, and Extended Depth of Focus Intraocular Lenses. J Refract Surg. 2016;32(4):273-80.

25. Alió JL, Plaza-Puche AB, Piñero DP, Amparo F, Rodríguez-Prats JL, Ayala MJ. Quality of life evaluation after implantation of 2 multifocal intraocular lens models and a monofocal model. J Cataract Refract Surg. $2011 ; 37(4): 638-48$ 